\title{
Penyusunan Asesmen Kebutuhan Anak Dengan Gangguan Pemusatan Perhatian Dan Hiperaktifitas (GPPH)
}

\author{
Onny Fransinata Anggara1, Satiningsih ${ }^{2}$ \\ ${ }^{1}$ Jurusan Psikologi \\ Fakultas Ilmu Pendidikan, Universitas Negeri Surabaya \\ ํㅡnyanggara@unesa.ac.id
}

\begin{abstract}
Children with hyperactive behavior are known as problem children. According to Amin (2012), children with attention deficit disorder and hyperactivity are forms of behavior that are encountered with symptoms of showing an uncontrollable attitude, reluctance to sit still, difficulty maintaining focus and concentration and eliciting impulsive behavior. GPPH experienced by children can trigger not optimal learning achievement as well as low levels of achievement and detection of poor psychomotor areas. This implication is the impact of obstacles in coordinating functioning, emotional response, interactional, and learning abilities that do not show a coordinating function. Furthermore, this implication is also related to the learning process in children with ADHD which is not as easy as in normal children in general. Thus, children with ADHD need special treatment by adjusting the personal needs of each child who has different needs even though they have the same ADHD problem. The purpose of this study was to identify the needs of children with ADHD, by compiling a needs assessment instrument. The research uses the Research \& Development $(R \& D)$ method with the ADDIE model. Based on the data obtained, it is known that the needs of ADHD children are handling in the Task performance, Adaptive, cognitive and emotional functioning areas. Based on the instruments that have been distributed, the 4 areas are the areas that most need to be given immediate treatment, both in the context of schools and therapy places.
\end{abstract}

Keywords: Attention Deficit and Hiperactivity Disorder (ADHD), Need Assessment

\begin{abstract}
Abstrak
Anak dengan perilaku hiperaktif dikenal sebagai anak bermasalah. Menurut Amin (2012) anak dengan gangguan pemusatan perhatian dan hiperaktif merupakan bentuk perilaku yang ditemui dengan gejala menunjukkan sikap tidak terkendali, enggan untuk duduk diam, kesulitan untuk menjaga fokus dan konsentrasi serta memunculkan perilaku yang impulsive. GPPH yang dialami oleh anak dapat memicu tidak maksimalnya prestasi belajar juga rendahnya tingkat prestasi dan deteksi buruknya area psikomotor. Implikasi tersebut merupakan dampak dari adanya kendala dalam coordination functioning, emotional response, interaksional,
\end{abstract}


dan learning ability yang tidak menunjukkan fungsi yang koordinatif. Lebih jauh, implikasi ini juga berkaitan dengan learning process pada anak dengan GPPH yang tidak semudah pada anak normal pada umumnya. Sehingga, anak dengan GPPH membutuhkan suatu perlakuan khusus dengan menyesuaikan kebutuhan personal dari masing-masing anak yang memiliki perbedaan kebutuhan meskipun memiliki problem GPPH yang sama. Tujuan penelitian ini adalah mengidentifikasi kebutuhan anak GPPH, dengan menyusun instrumen asesmen kebutuhan. Penelitian menggunakan metode Research \& Development (R\&D) dengan model ADDIE. Berdasarkan data yang diperoleh, diketahui bahwa kebutuhan pada anak GPPH adalah penanganan pada area Task performance, Adaptive, cognitive dan emotional functioning. Berdasarkan instrument yang telah disebar, maka 4 area tersebut merupakan area yang paling membutuhkan untuk segera diberi penanganan atau treatment baik dalam konteks sekolah maupun tempat terapi.

Kata kunci: Gangguan Pemusatan Perhatian dan Hiperaktifitas (GPPH), Asesmen Kebutuhan

\section{Pendahuluan}

Pada Diagnostic and Statistical Manual of Mental Disorder edisi ke-4 (DSM-IV) gangguan Pemusatan Perhatian dan Hiperaktifitas (GPPH) atau lebih dikenal pula dengan istilah ADHD yang dikelompokkan sebagai disruptive behavior disorder. Ini muncul karena adanya kesamaan dalam karakteristik dan gejala yang muncul pada para penderitanya, yaitu mengalami hambatan yang besar dalam memunculkan perilaku yang adaptif serta terkendala dalam melakukan penyesuaian secara sosial. Perilaku pada anak dengan GPPH cenderung impulsif, tidak teratur, excessive, agresifitas cenderung tinggi, disturbing, dan kendali emosional yang cenderung kurang stabil. Gejala tersebut membuat para anak dengan GPPH akan cenderung mengalami hambatan dalam dalam berinteraksi, melakukan kooperasi dengan lingkungan sekitarnya yang mana ini merupakan salah satu bagian esensial dalam fase kehidupan sosial seorang anak (Whalen \& Henker, 1992 dalam Barkley, 2004).

Gangguan Pemusatan Perhatian dan Hiperaktifitas (GPPH) atau Attention Deficit Hyperactivity Disorder (ADHD) merupakan keadaan yang diidentifikasikan dengan munculnya suatu hambatan dalam memfokuskan konsentrasi pada satu objek, timbulnya perilaku yang tidak terkendali cenderung excessive, kesulitan duduk diam, dan cenderung impulsif, yang mana hal ini bisa muncul pada suatu 
situasi dengan frekuensi yang intesif (Kementerian Kesehatan RI, 2011). American Psychiatric Association memprediksi bahwa 3 sampai 7 anak dari total 100 anak sekolah memiliki indikasi menderita GPPH (Kementerian Kesehatan RI, 2011). Penelitian lain yang mendukung juga menyebutkan prevalensi GPPH pada anak di seluruh dunia berkisar 4-7\% (Spencer, 2008). Pada temuan berikutnya, Pineda (1999) menyampaikan dalam studinya bahwa anak dengan GPPH khususnya dalam konteks sekolah memiliki presentasi 3-10\% (Kementerian Kesehatan RI, 2011). DSM IV-TR melaporkan juga bahwa terkait presentase dari kasus GPPH ini adalah sebesar 2-7\% diantara anak usia sekolah (Forgey dan DeJong, 2008).

Berdasarkan data sebelumnya, dapat dipahami bahwa riset yang berhubungan dengan prevalensi atau presentase jumlah anak yang mengalami GPPH di Indonesia masih minim, artinya hingga hari ini belum diperoleh kuantifikasi yang pasti terkait jumlah kasus anak yang mengalami GPPH di Indonesia (Novriana et al., 2014). Temuan berikutnya dari, Badan Penelitian dan Pengembangan Fakultas Kedokteran Universitas Andalas pada tahun 2006, dipaparkan bahwa terdapat 33\% siswa pada tingkat Sekolah Dasar yang dinyatakan menunjukkan gejala-gejala terkait gangguan pada area emosional serta perilaku, lebih lanjut riset ini memaparkan data kuantifikasinya bahwa subjek yang diteliti adalah sekitar 696 siswa Sekolah Dasar dari 4 provinsi di Indonesia dengan ratarata nilai rapor kurang dari 6 (Mahabbati, 2013).

Anak dengan GPPH ini membutuhkan suatu treatment khusus baik bersifat individual maupun yang bersifat komunal demi mendapatkan pendidikan serta perlakuan untuk dapat memenuhi hak-haknya. Proses pembelajaran untuk anak dengan GPPH memiliki kompleksitas pada level yang berbeda jika dibandingkan dengan anak normal. Menurut Saptono (2009, dalam Tri, dkk: 2013) menyatakan bahwa Gangguan Pemusatan perhatian dan Hiperaktfitas pada anak dapat menyebabkan prestasi atau capaian belajar menjadi tidak optimal bahkan pada tingkat Pendidikan level dasar akan mengakibatkan anak menunjukkan performa yang rendah dan juga penampilan psikomotorik buruk. Dampak ini merupakan suatu implikasi dari adanya hendaya dalam coordination functioning, emotional respons, interaksional, dan learning skill. Penatalaksanaan atau penanganan pada 
anak dengan Gangguan Pemusatan Perhatian dan Hiperaktifitas tergambar sebagai suatu sequence dalam aktivitas yang tersusun secara terstruktur, sistematis dan tertuang dalam suatu dokumen atau program tertentu yang penatalaksanaannya berorientasi pada pemenuhan kebutuhan dan pencapaian tugas-tugas perkembangan pada anak khususnya yang mengalami GPPH. Oleh sebab itu aspekaspek terkait dengan planning, programming, composing, purposing, criteria, evaluating, dan responsibility yang dapat terpenuhinya kebutuhan perkembangan yang melandasi pencapaian tugas perkembangan anak yang menjadi target layanan program tersebut. Oleh sebab itu, diperlukan suatu instrumen asesmen kebutuhan yang tepat dan akurat yang akan menjadi bagian dalam pengembangan program terkait penatalaksanaan pada anak dengan Gangguan Pemusatan Perhatian Hiperaktifitas.

Kegiatan untuk penanganan atau penatalakasanaan pada Anak dengan GPPH harus merupakan upaya konkrit yang sistemik, strategis dan kolaboratif dengan aktivitas pembelajaran atau terapis menuju tercapainya proses dan hasil yang diharapkan. Mengenai konsep tersebut, maka efektivitas suatu program bagi anak dengan GPPH sangat ditentukan oleh para orang tua, guru, terapis dan pemerhati yang mampu menunjukkan kepedulian terhadap pemenuhan kesejahteraan para anak dengan GPPH. Kepedulian dapat terwujud dari ketepatan dalam merumuskan rangkaian program penanganan atau penatalaksanaan untuk anak dengan GPPH, karena disisi lain menurut Hargreaves (1982) menyatakan banyak institusi kurang memberikan perhatian pada peserta didik khususnya pada aspek martabat atau harga diri yang rendah, ini memberi implikasi pada anak atau peserta didik yaitu munculnya penolakan terhadap proses sekolah, terapi atau penanganan yang lain dan akhirnya berujung pada keputusan untuk meninggalkan institusi atau drop out. Menanggulangi hal tersebut, maka perlu merumuskan dengan tepat hal-hal yang dibutuhkan untuk penanganan secara tepat pada anak dengan GPPH.

Secara khusus, Barkley \& Murphy dalam Jerome Sattler, 2002: 266-267) mendeskripsikan area asesmen kebutuhan untuk Anak dengan GPPH agar dapat membantu dalam menyelesaikan tugas-tugas perkembangan adalah 
penatalaksanaan pada area-area berikut ini Cognitive Deficit, Adaptive Functioning Deficit, Languange Deficit, Task Performance Deficit, Motor and physical Development deficit, Emotional Deficit, School Performance Deficit, dan Health and Accidental Injury Deficit.

Menurut Permanarian (2005) asesmen sendiri adalah suatu proses dan tahapan untuk memperoleh informasi secara utuh terkait dengan kebutuhan seorang anak yang nantinya dimanfaatkan sebagai bagian dalam proses penyusunan program pada anak secara individual maupun secar komunal. Meskipun asesmen pertama kali dilakukan sebelum kegiatan atau program dilakukan, namun sesungguhnya sebuah proses asesmen berlangsung selama proses berlangsung. Selain itu, Zainal Alirnin (2003) mengemukakan dalam temuannya bahwa suatu asesmen merupakan proses yang sistematis dalam mengumpulkan informasi mengenai seorang anak yang berkaitan dengan kondisi atau situasi yang dialaminya. Dalam konteks pendidikan, asesmen memiliki peran dalam mengidentifikasi kemampuan, kelebihan dan kesulitan yang dihadapi seseorang baik pada konteks anak, remaja maupun dewasa, ini merupakan dasar dalam menentukan apa yang sesungguhnya dibutuhkan oleh seorang individu sehingga dapat menyelesaikan tugas ataupun kompetensi yang diharapkan. Kemudian informasi yang diperoleh dari hasil asesmen, dapat dimanfaatkan oleh berbagai pihak terkait seperti seorang praktisi, guru atau terapis, yang nantinya akan terbantu dalam menentukan dan menyusun program pembelajaran atau penatalaksanaan yang konkrit sesuai dengan kebutuhan dari masing-masing individu terkait penanganan dari gangguan atau permasalahan yang dihadapi.

Anak-anak dengan GPPH sangat membutuhkan layanan yang tepat dan sesuai, oleh karena itu dibutuhkan adanya asesmen agar pelayanan yang diberikan sesuai dengan kebutuhan mereka. Asesmen pada anak berkebutuhan khusus dalam hal ini adalah anak dengan GPPH merupakan suatu langkah yang penting, esensial dan fundamental dalam menentukan tahapan-tahapan dan instrumen yang akan digunakan untuk menjawab tantangan dalam memberikan layanan, meyusun program atau penatalaksanaan khususnya bagi anak-anak ADHD. 
Hal tersebut merupakan tantangan dalam dunia perkembangan anak dalam membantu memberikan solusi untuk memecahkan permasalahan dalam bagaimana mendeteksi dan menangani anak dengan gangguan hiperaktif dan penatalaksanaannya dengan membantu mengembangkan asesmen kebutuhan pada anak dengan ADHD atau dikenal juga anak dengan Gangguan Pemusatan Perhatian dan Hiperaktifitas (GPPH). Itulah sebabnya menjadi sebuah hal yang penting untuk dapat menyusun suatu instrument terkait asesmen kebutuhan pada anak dengan GPPH, sehingga para orang tua, guru dan praktisi dapat menyusun program penanganan dan penatalaksanaan secara individual yang tepat untuk menangani anak dengan GPPH tersebut.

\section{Metode}

Metode dalam penelitian ini menggunakan jenis Research and Development (R\&D) dengan memanfaatkan model ADDIE (Analysis, Design, Development, Implementation, Evaluation). Penggunaan Model ADDIE bertujuan untuk mengembangkan asesmen kebutuhan bagi anak yang mengalami ADHD atau GPPH, dengan menyusun skala berdasarkan teori dari Barkley dan Murphy. Ada 5 tahapan dalam model ADDIE yaitu Analysis (Analisis), Design (Perancangan), Development (Pengembangan), Implementation (Implementasi) dan Evaluation (Evaluasi) Merupakan model Research and Development yang lebih komprehensif, rasional dan lebih lengkap dibanding model lainnya jika berdasarkan pada tahapan langkah-langkah pengembangan produk.

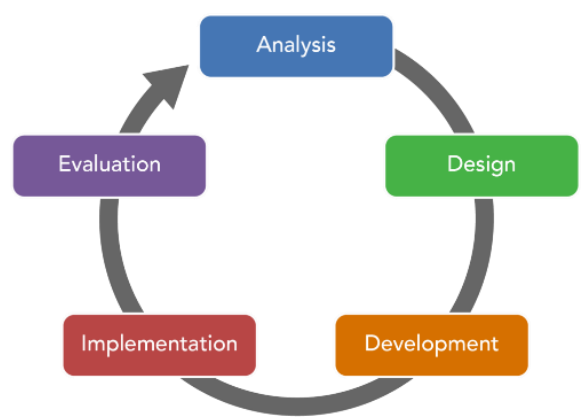

Gambar 1. Alur ADDIE 
Subjek penelitian dalam penyusunan asesmen kebutuhan ini adalah 30 orang tua yang memiliki anak dengan Gangguan Pemusatan Perhatian Hiperaktifitas (GPPH), serta melibatkan para pakar atau ahli dibidang perkembangan anak dengan GPPH. Teknis analisis menggunakan bantuan dari JASP untuk membantu melihat reliabilitas dari instrument asesmen kebutuhan yang akan disusun, skala instrument menggunakan skala likert dari angka 1 sampai 4 . Angka satu untuk kategori Kurang Butuh, Dua untuk kategori Sedikit Butuh, 3 untuk kategori Butuh dan Empat untuk kategori sangat butuh. Validitas dan reliabilitas data diperoleh dari telaah pakar perkembangan dan menggunakan bantuan software JASP.

\section{Hasil dan Pembahasan}

Berdasarkan prosedur pengembangan model ADDIE, tahap Analisis difokuskan pada telaah konseptual terkait pengembangan pada instrumen asesmen kebutuhan berdasarkan konsep teori Barkley \& Murphy (2002) yang berkaitan dengan aspek - aspek pada GPPH yang perlu menjadi perhatian. Telaah konseptual terkait asesmen kebutuhan ini dilanjutkan dengan tahap desain yang menghasilkan konstruk instrumen sebagai berikut.

\begin{tabular}{ll}
\hline No & \multicolumn{1}{c}{ Aspek } \\
\hline $\mathbf{1}$ & Cognitive Deficit \\
\hline $\mathbf{2}$ & Adaptive Functioning Deficit \\
\hline $\mathbf{3}$ & Languange Deficit \\
\hline $\mathbf{4}$ & Task Performance Deficit \\
\hline $\mathbf{5}$ & Motor and physical Development deficit \\
\hline $\mathbf{6}$ & Emotional Deficit \\
\hline $\mathbf{8}$ & School Performance Deficit \\
\hline
\end{tabular}

Tabel 1. Aspek Kebutuhan Pada Anak dengan GPPH

Berdasarkan konstruk instrument yang telah dirancang pada tahap analysis, prosedur selanjutnya adalah terkait dengan pengembangan atau pada tahap Development. Pada tahap ini, aitem dari instrumen mulai disusun dengan berpedoman pada indikator yang dikonstruk pada setiap aspek kebutuhan berdasarkan teori dari Barkley dan Murphy. Terdapat 30 butir instrumen AKAG 
(Asesmen Kebutuhan Anak dengan GPPH) dengan skala 4 kategeori Sangat Butuh; 3 kategori Butuh; 2 kategori Sedikit Butuh; dan 1 kategori Kurang Butuh.

Sebagai bagian pemenuhan aspek validitas isi dan konstruk, draft awal dari instrument ini dilakukan FGD dengan melibatkan 30 orang tua yang memiliki anak dengan GPPH. Selain itu, juga dimintakan telaah pada para pakar dalam bidang perkembangan anak dan pemerhati anak dengan GPPH. Kedua tahapan tersebut dilakukan untuk memeriksa keterpenuhan validitas isi dan validitas konstruk logis instrumen. Informasi dari penilaian pakar dan pengguna melalui FGD terhadap instrumen yang disusun dapat dicermati pada table berikut:

\begin{tabular}{clcc}
\hline No & Penilaian Konstruk Instrumen & Penilaian Pakar & FGD \\
\hline $\mathbf{1}$ & Kejelasan petunjuk pengisian & 4 & Baik \\
\hline $\mathbf{2}$ & Kejelasan aspek dan indicator & 4 & Baik \\
\hline $\mathbf{3}$ & Kejelasan aitem & 4 & Baik \\
\hline $\mathbf{4}$ & Kemudahan menjawab & 5 & Sangat Baik \\
\hline $\mathbf{5}$ & Kemudahan dalam membaca & 4 & Baik \\
\hline $\mathbf{6}$ & Kemudahan dalam memahami aitem & 4 & Baik \\
\hline $\mathbf{7}$ & Kecukupan jumlah aitem & 4 & Baik \\
\hline $\mathbf{8}$ & Bahasa Indonesia yang baku & 4 & Baik \\
\hline $\mathbf{9}$ & Standar format dan layout & 3 & Baik \\
\hline $\mathbf{1 0}$ & Simplicity rumusan aitem & 4 & Baik \\
\hline
\end{tabular}

Tabel 2. Penilaian Ahli terhadap Instrumen AKAG

Pada tabel 2 menunjukkan hasil telaah dari para pakar dan juga ada hasil dari FGD yang telah dilakukan untuk terhadap kualitas konstruk instrumen AKAG, dan masing-masing pihak relatif memberikan skor sangat baik dan juga pada tarag baik pada penilaian pakar atau ahli dalam bidang perkembangan anak dengan GPPH dan juga pada sesi Focus Group Discussion (FGD). Selain itu, estimasi reliabilitas Alpha Cronbach terhadap instrumen AKAG menggunakan bantuan dari aplikasi program JASP. Rekapitulasi hasil analisis estimasi reliabilitas dilaporkan sebagai berikut: 


\begin{tabular}{lcc}
\hline \multicolumn{1}{c}{ Tahap } & $\begin{array}{c}\text { Indeks Reliabilitas } \\
(\mathbf{N}=\mathbf{1 0})\end{array}$ & Klasifikasi \\
\hline Uji Coba & 0,9021 & Sangat tinggi \\
\hline Implementasi & 0,9480 & Sangat tinggi \\
\hline
\end{tabular}

Tabel 3. Uji reliabilitas $\mathrm{N}=10$

Data tabel menunjukkan reliabilitas instrumen AKAG yang dikembangkan memiliki indeks reliabilitas Alpha >0,90; baik yang diuji dengan cuplikan sampel kecil $(\mathrm{N}=10)$ maupun setelah dilakukan pengujian pada seluruh sampel baik dalam tahap ujicoba maupun tahapan implementasi. Pada hasil reliabilitas untuk sampel $\mathrm{N}=30$ juga diperoleh nilai yang sangat tinggi terkait reliabilitasnya.

\begin{tabular}{lcc}
\hline \multicolumn{1}{c}{ Tahap } & $\begin{array}{c}\text { Indeks Reliabilitas } \\
(\mathbf{N = 3 0 )}\end{array}$ & Klasifikasi \\
\hline Uji Coba & 0,9110 & Sangat tinggi \\
\hline Implementasi & 0,9301 & Sangat tinggi \\
\hline
\end{tabular}

Tabel 4. Uji reliabilitas $\mathrm{N}=30$

Tahap implementasi penggunaan instrumen AKAG adalah dengan memberikan instrument untuk diisi oleh orang tua yang menilai kondisi atau kebutuhan masing-masing anak, sesuai dengan gejala atau simtom yang ditunjukkan secara personal. Hasil dari pengisian instrument oleh orang tua anak dengan GPPH menghasilkan informasi dan data yang dapat dilihat pada table berikut ini:

\begin{tabular}{clc}
\hline No & \multicolumn{1}{c}{$\begin{array}{c}\text { Penanganan yang dibutuhkan anak dengan GPPH } \\
\mathbf{N = 3 0}\end{array}$} & Skor \\
\hline $\mathbf{1}$ & Sulit berkonsentrasi untuk waktu yang lama & 119 \\
\hline $\mathbf{2}$ & Anak mampu untuk berlatih mengendalikan rasa marah & 119 \\
\hline $\mathbf{3}$ & Mudah bosan dalam menyelesaikan pekerjaan & 107 \\
\hline $\mathbf{4}$ & $\begin{array}{l}\text { Anak mampu mengerti instruksi tanpa pengulangan yang } \\
\text { intensif }\end{array}$ & 103 \\
\hline $\mathbf{5}$ & $\begin{array}{l}\text { Mudah teralihkan saat mengerjakan satu penugasan atau } \\
\text { aktivitas }\end{array}$ & 100 \\
\hline $\mathbf{6}$ & Emosi marah yang meledak-ledak & 100 \\
\hline $\mathbf{7}$ & Minat yang terbatas & 98 \\
\hline
\end{tabular}




\begin{tabular}{cll}
\hline $\mathbf{8}$ & Mengurangi perilaku impulsive & 97 \\
\hline $\mathbf{9}$ & Anak tidak melakukan perilaku-perilaku yang menganggu & 97 \\
\hline $\mathbf{1 0}$ & $\begin{array}{l}\text { Anak mampu mengingat informasi dalam jangka pendek } \\
\text { atau jangka Panjang }\end{array}$ & 95 \\
\hline $\mathbf{1 1}$ & Kebiasaan dalam menunda penyelesaian tugas & 93 \\
\hline $\mathbf{1 2}$ & Kemampuan berbahasa yang belum memadai & 87 \\
\hline $\mathbf{1 3}$ & $\begin{array}{l}\text { Anak sulit untuk duduk diam pada situasi yang diharapkan } \\
\text { untuk itu }\end{array}$ & 86 \\
\hline $\mathbf{1 4}$ & Menunjukkan perilaku mengganggu & 85 \\
\hline $\mathbf{1 5}$ & Kemampuan dalam Penggunaan dan efektifitas Waktu & 85 \\
\hline $\mathbf{1 6}$ & Anak belajar bertanggung jawab & 85 \\
\hline $\mathbf{1 7}$ & Mengarahkan diri untuk menyelesaikan suatu problem & 83 \\
\hline $\mathbf{1 8}$ & Kesulitan merespon & 79 \\
\hline $\mathbf{1 9}$ & Membutuhkan tutor di sekolah & 76 \\
\hline $\mathbf{2 0}$ & Kesulitan mengekspresikan emosi dengan tepat & 74 \\
\hline $\mathbf{2 1}$ & Anak tidak lagi bermain dengan kasar & 68 \\
\hline $\mathbf{2 2}$ & Kemampuan anak dalam membaca & 65 \\
\hline $\mathbf{2 3}$ & Memiliki tulisan tangan yang jelek & 64 \\
\hline $\mathbf{2 4}$ & Sering mengulang kelas & 63 \\
\hline $\mathbf{2 5}$ & Kemampuan anak dalam berhitung & 60 \\
\hline $\mathbf{2 6}$ & Mengalami kesulitan untuk tidur & 56 \\
\hline $\mathbf{2 7}$ & Kemampuan anak dalam melakukan pengejaan & 54 \\
\hline $\mathbf{2 8}$ & Mengalami kesulitan untuk menggambar & 40 \\
\hline $\mathbf{2 9}$ & Sering mengalami kondisi sakit & 40 \\
\hline $\mathbf{3 0}$ & Sering jatuh saat tidur & 39 \\
\hline
\end{tabular}

Keterangan: Angka pada table diatas adalah Peringkat yang menggambarkan tingkat kebutuhan paling mendesak untuk ditangani pada anak dengan GPPH.

Tabel diatas menunjukkan peringkat dari isu atau problem yang perlu diberikan penanganan pada anak dengan GPPH. Berdasarkan table tersebut, aspek yang paling mendesak untuk disusun program penanganan adalah terkait Task Performance Functioning menempati urutan pertama, lalu selanjutnya adalah terkait dengan kemampuan adaptive functioning dari anak dengan GPPH lalu yang ketiga adalah cognitive functioning dan yang keempat adalah emotional functioning. Sedangkan aspek yang lain dari 30 data yang diperoleh menunjukkan derajat yang kurang begitu kuat dibandingkan 4 aspek diatas.

Hal ini secara tidak langsung menunjukkan dan mengarahkan para guru, pemerhati dan pakar yang menangani anak dengan GPPH untuk membuat program individual sesuai dengan kebutuhan dari masing-masing anak. Sehingga penanganan menjadi lebih tepat dan mampu membantu ketercapaian dari hasil yang diharapkan. Butir kebutuhan terintens yang teridentifikasi dari hasil table di atas, mampu memberikan bantuan bagi para orang tua, guru, pakar dan pemerhati dapat 
menyusun program penanganan atau penatalaksanaan secara individual sehingga dapat teratasi dengan lebih tepat.

\section{Kesimpulan dan Saran}

Instrumen Asesmen Kebutuhan Anak dengan GPPH yang disusun dan dikembangkan pada riset ini, berdasarkan hasil penilaian dari para pakar dan penilaian pengguna (30 orang tua yang memiliki anak dengan ADHD) juga dikuatkan dengan bukti empirik yang menggambarkan bahwa instrument yang sudah disusun dapat memenuhi validitas konstruk dan terjaga pada tingkat reliabilitasnya. Dengan hal tersebut, maka dapat ditarik kesimpulan asesmen yang disusun oleh peneliti dapat memenuhi syarat sebagai salah satu instrumen asesmen kebutuhan pada anak dengan GPPH sehingga dapat membantu dalam merancang program atau penatalaksanaan yang lebih tepat guna menangani anak dengan GPPH. Instrumen ini dapat digunakan oleh orang tua, tenaga pengajar atau Terapis untuk mengumpulkan data terkait aspek-aspek kebutuhan anak dengan GPPH dalam rangka penatalaksanaan dan penanganan anak dengan GPPH.

Berdasarkan penelitian dan hasil yang telah didapatkan dari rangkaian kegiatan yang telah dilakukan, maka dapat disampaikan beberapa saran. Saran bagi orang tua, guru dan pemerhati anak dengan GPPH adalah agar pihak-pihak terkait tersebut dapat mengidentifikasi dan menentukan secara tepat terkait penanganan yang paling dibutuhkan anak dengan GPPH melalui terlebih dahulu memetakan kesulitan atau isu-isu yang dialami oleh anak menggunakan instrument asesmen kebutuhan atau AKAG ini. Saran bagi sekolah atau tempat terapi yaitu agar penelitian ini dapat dijadikan masukan bagi pihak sekolah maupun tempat terapi anak dengan GPPH untuk dapat mengimplementasikan Instrumen AKAG yang telah dibuat, sehingga dari hasil asesmen kebutuhan yang telah diperoleh mampu untuk merumuskan aktivitas atau program yang bersifat individual guna menangani isu-isu utama yang dianggap paling urgensi paling tinggi pada diri anak yang perlu untuk diselesaikan.

Saran untuk penelitian selanjutnya adalah agar peneliti berikutnya lebih mendalami terkait masing-masing aspek pada isu utama anak dengan GPPH untuk 
kemudian mengidentifikasi secara spesifik serta menyusun instrument yang lebih komprehensif lagi.

\section{Daftar Pustaka}

Barkley, Russel A. \& Murphy, Kevin R. (2006). Attention-Deficit Hyperactivity. Disorder A Clinical Workbook Third Edition. United States: The Guilford.

Dean, Colin O. 2009. Distinguish Disability Parents, Privilage and Special Education. Chicago: The University of Chicago Press.

Desforges C \& Abouchaar. 2003. The Impact of Parental Involvement, Parental Support and Family Education on Pupil Achievement and Adjusment : a literature review. Research Report. No. 43. Queens Printer.

Firdaus, E. 2010. Pendidikan Inklusif dan Implementasinya di Indonesia. Makalah. Tidak diterbitkan. Disampaikan dalam Seminar Nasional Pendidikan di Universitas Jendral Soedirman Purwokerto.

Hayes, S.C, Strosahl, KD, Wison, K.G. (1999). Acceptance and Commitment theraphy: anexperimental approach to behaviour change. The Guilford Press. New York.

Hendriani, W. 2006. Penerimaan Keluarga terhadap Individu yang mengalami KeterbeakanganMental. Laporan penelitian tidak diterbitkan. Surabaya : Fakultas Psikologi Unair.

Johnson, BH \& Skjorten, DM. 2003. Pendidikan Kebutuhan Khusus. Sebuah Pengantar,terjemahan. Bandung : Program Pasca Sarjana UPI

Karunia, Ana, Ika Yuniar Cahyanti (2016) Pengaruh Psikoedukasi tentang Pengetahuan ADHD terhadap Kemampuan Guru dalam Melakukan Deteksi Dini Masalah ADHD pada Siswa dan Keterampilan Intervensi Kelas. JurnalINSAN Vol. 01 No. 01, Juni 2016

Melinda Hospital. 2013. Anak Hiperaktif Penyebab dan Cara Mengatasinya. http://www.melindahospital.com/modul/user/detail_artikel.php?id=1001_ Anak-Hiperaktif:-Penyebab-dan-Cara-Mengatasinya

Shaughnessy, J, Zechmeister E.B, Zechmeister J.S. Metodologi Penelitian Psikologi 2007. Edisike 7. Yogyakarta : Pustaka Pelajar

Tri, Ayu Anjani, Najlatun Naqiyah, Sutijono, Hermien Laksmiwati (2013) Studi 
Kasus Tentang Konsentrasi Belajar Pada Anak Adhd (Attention Deficit Hyperactivity Disorder) Di Sdit At-Taqwa Surabaya Dan Sdn V Babatan Surabaya .Jurnal BK UNESA, Volume 1 Edisi2, 125-135

Weiss, J.A, Cappadocia,M.C, MacMullin J.A, Vielli,M\& Lunsky,Y. 2013. The Impact of Child Problem Behaviour of Children with ASD on parent mental health. Psychological Acceptance and Empowerment. Vol 3. 145-163

Whittingham K, Sofronoff K, Sheffield J.K. 2006. Stepping Stones Triple P: A pilot study to evaluate acceptability of the program by parents of a child diagnosed with an Autism Spectrum Disorder. Research in Developmental Disabilities 27 (2006). 354-360.

Wiguna, T (2007) Gejala, Latar Belakang Permasalahan dan Kebutuhan Anak Dengan Gangguan Pemusatan Perhatian Dan Hiperaktivitas (GPPH) Dan Gangguan Spejtrum Autistik. Makalah Pada Simposium Sehari Kesehatan Jiwa Dalam Rangka menyambut Hari Kesehatan Sedunia, (online). www.idijakbar.com 